Article

\title{
Bonding Strength Characteristics of FA-Based Geopolymer Paste as a Repair Material When Applied on OPC Substrate
}

\author{
Warid Wazien Ahmad Zailani ${ }^{1,2}{ }^{(0)}$, Aissa Bouaissi ${ }^{3, *}$, Mohd Mustafa Al Bakri Abdullah ${ }^{1, *}$, \\ Rafiza Abd Razak ${ }^{1}$, Sorachon Yoriya ${ }^{4}$, Mohd Arif Anuar Mohd Salleh ${ }^{1}$, \\ Mohd Remy Rozainy M. A. Z. ${ }^{5}$ and Hamzah Fansuri ${ }^{6}$ \\ 1 Center of Excellence Geopolymer and Green Technology (CEGeoGTech), School of Materials Engineering, \\ Universiti Malaysia Perlis (UniMAP), Perlis 01000, Malaysia; warid.wazien92@yahoo.com (W.W.A.Z.); \\ rafizarazak@unimap.edu.my (R.A.R.); arifanuar@unimap.edu.my (M.A.A.M.S.) \\ 2 Faculty of Civil Engineering, Universiti Teknologi Mara Shah Alam, Selangor 40450, Malaysia \\ 3 School of Marine Science and Engineering, University of Plymouth, Plymouth PL4 8AA, UK \\ 4 National Metal and Materials Technology Center (MTEC), National Science and Technology Development \\ Agency (NSTDA), Pathum Thani 12120, Thailand; sorachy@mtec.or.th \\ 5 School of Civil Engineering, Engineering Campus, Universiti Sains Malaysia (USM), Penang 11800, Malaysia; \\ ceremy@usm.my \\ 6 Department of Chemistry, Institut Teknologi Sepuluh Nopember (ITS), Surabaya 60111, Indonesia; \\ h.fansuri@chem.its.ac.id \\ * Correspondence: aissabouaissi@yahoo.fr (A.B.); mustafa_albakri@unimap.edu.my (M.M.A.B.A.)
}

Received: 9 April 2020; Accepted: 7 May 2020; Published: 10 May 2020

\begin{abstract}
This investigative study aims to study the mechanical and morphological properties of fly ash (FA)-based geopolymer paste as a repair material when applied on ordinary Portland cement (OPC) overlay concrete. The first part of this study investigates the optimal mix design of FA-based geopolymer paste with various $\mathrm{NaOH}$ concentrations of $8,10,12$, and $14 \mathrm{M}$, which were used later as a repair material. The second part studies the bonding strength using a slant shear test between the geopolymer repair material and OPC substrate concrete. The results showed that a shorter setting time corresponds to the higher $\mathrm{NaOH}$ molarity, within the range of 53 and $30 \mathrm{~min}$ at 8 and $14 \mathrm{M}$, respectively. The compressive strength of FA-based geopolymer paste was found to reach $92.5 \mathrm{MPa}$ at 60 days. Also, from the slant shear test results, prism specimens with $125 \mathrm{~mm}$ length and $50 \mathrm{~mm}$ wide have a large bond strength of $11 \mathrm{MPa}$ at $12 \mathrm{M}$. The scanning electron microscopy/energy-dispersive X-ray (SEM/EDX) analysis showed that the OPC substrate has a significant effect on slant shear bond strength, where the presence of free cations of $\mathrm{Ca}^{2+}$ on the OPC substrate surface contributed to the formation of calcium alumina-silicate hydrate gel (C-A-S-H) by building various cross-links of Ca-O-Si.
\end{abstract}

Keywords: fly ash; geopolymer repair material; compressive strength; bonding strength; bonding zone

\section{Introduction}

Massive efforts and attempts are made to reduce the share of using ordinary Portland cement (OPC) as the main source of concrete production. It was reported that the second most used material after water is concrete [1]. However, a huge quantity of energy is required during the production of Portland cement (PC) concrete, which in turn contributes to the emission of large amounts of greenhouse gases [2]. A few decades back, a new concept of so-called geopolymers was first described by Davidovits in 1978 [3]. Also known as alkali-activated materials, geopolymers have been widely investigated in 
many research works, due to their durability, physical and chemical properties, such as high strength, good corrosion resistance to aggressive environments, and ability to withstand high temperature [4-6]. Throughout the years, numerous studies have been conducted to expand wider the use of geopolymers, whose potential use in infrastructure rehabilitation was proposed by Pacheco-Torgal et al. [7]. However, limited studies can be found in the field of repair and rehabilitation geopolymer materials, in particular, in relation to the bonding mechanism when it is used as a repairing layer or as binding material to ensure its adhesion against OPC substrate.

Much research has investigated the manufacturing of geopolymers using various precursors, such as fly ash, tungsten mine waste mud, granulated and blast furnace slag, where different alkaline solutions were used as chemical activators [8-10]. Pacheco-Torgal et al. [5] investigated the production of a geopolymer using tungsten mine waste, where calcium hydroxide was added as an additive to the geopolymeric mixture. Their results showed a high bonding strength of the geopolymeric binders formed when compared to that of commercial repair products. Tanakorn et al. [11] studied bond strengths of a geopolymer mix made from fly ash and of slag, and the results revealed that a high bonding strength ( $>10 \mathrm{MPa})$ can be obtained when sodium hydroxide with sodium silicate solution is used as an alkali activator, which was in contrast to those mixes where sodium hydroxide solution or sodium silicate solution were independently used. Hani et al. [12] investigated the bond strength of a high calcium-based geopolymer repair material (GRM) using both slant shear and split tensile tests. Their findings showed a remarkable bonding strength can be achieved for their produced geopolymer material when compared to OPC-based repair material and ultra-high performance fibre concrete (UHPFC). Another study by Laskar et al. [13] reported that slag-based geopolymer can be a significant material to be used as concrete repairing binder. A similar study conducted by Collins and Sanjayan [14] showed that in the production of slag-based geopolymer concrete, the replacement of $10 \%$ of slag by ultra-fine fly ash, ultra-fine slag and condensed silica fume enhanced its strength and workability. However, the same authors stated that the increase in fineness of the binders results in low workability and accelerates the setting time of geopolymer mortar or concrete when compared to binders with lower fineness [14].

Based on the literature described above, there is a lack of studies that clearly describe the main bonding mechanism between geopolymer repair material and OPC concrete substrate. In this study, the authors attempted to investigate fresh and hardened properties of high calcium fly ash-based geopolymer as a repairing material, including setting time, morphological analysis, and a bonding strength mechanism against OPC substrate. The effect of variation of alkali activator concentration has also been investigated.

\section{Experimental Program and Procedure}

\subsection{Materials}

Table 1 displays the chemical properties of fly ash (FA) and OPC, which were determined by using X-ray fluorescence analysis. Class F FA as classified by American Society for Testing and Materials (ASTM C618) [15] obtained from the thermal power plant at Manjung Power-plant, Malaysia. Sodium hydroxide pellets with an approximate purity of $99 \%$ were used to prepare an alkali activator solution. Sodium hydroxide solution $(\mathrm{NaOH})$ with different concentrations of $6 \mathrm{M}, 8 \mathrm{M}, 10 \mathrm{M}$, and $14 \mathrm{M}$ was prepared by dissolving sodium hydroxide pellets in a distilled water and leaving it for $24 \mathrm{~h}$ before being used. Alkali activator solutions were prepared by mixing sodium hydroxide solution with sodium silicate $\left(\mathrm{Na}_{2} \mathrm{SiO}_{3}\right)$ in a mass ratio of 2.5 , which was previously used for producing fly ash-based geopolymer material $[1,16]$. The sodium silicate solution was obtained from South Pacific Chemical Industries Sdn. Bhd. (SPCI), in Malaysia, with the chemical composition of $\mathrm{SiO}_{2}=30.1 \%, \mathrm{Na}_{2} \mathrm{O}=9.4 \%$ and water $\left(\mathrm{H}_{2} \mathrm{O}\right) 60.5 \%$ by mass. The mass ratio binder-to-liquid (alkali activator) of all mixes was kept at 2.0, which was suggested based on previous work [12,17,18]. 
Table 1. Chemical composition of fly ash and ordinary Portland cement (OPC).

\begin{tabular}{cccccccccc}
\hline Materials & $\mathrm{SiO}_{2}$ & $\mathrm{Al}_{\mathbf{2}} \mathrm{O}_{3}$ & $\mathrm{Fe}_{2} \mathrm{O}_{3}$ & $\mathrm{CaO}$ & $\mathbf{M g O}$ & $\mathbf{K}_{\mathbf{2}} \mathrm{O}$ & $\mathrm{TiO}_{2}$ & $\mathrm{SO}_{3}$ & LOI \\
\hline Fly ash (\%) & 38.40 & 14.50 & 19.57 & 18.4 & 3.6 & 1.71 & 1.00 & 1.56 & 1.05 \\
OPC (\%) & 14 & 3 & 4.39 & 72.24 & - & 1.01 & 0.3 & 4.52 & 0.065 \\
\hline
\end{tabular}

\subsubsection{Mix Proportions of Fly Ash (FA)-Based Geopolymer Paste}

In this investigative study, a geopolymer mix was prepared in which the binder consists of high calcium fly ash. In the fly ash-based geopolymer paste, 12 samples of $50 \mathrm{~mm} \times 50 \mathrm{~mm} \times 50 \mathrm{~mm}$ cube for each selected $\mathrm{NaOH}$ concentration were cast. A total of 48 cubic specimens were cast and tested for the compression test at $3,14,28$, and 60 days, where the average of three samples was considered.

\subsubsection{Mix Proportion of Ordinary Portland Cement (OPC) Concrete Substrate}

A mix design of OPC concrete was used to prepare the substrate, which later was used for slant shear with fly ash-based geopolymer repair material produced. Table 2 summarizes the mix proportion and strength of OPC concrete. The fine aggregate consisted of local river sand, while the coarse aggregate was crushed limestone gravel with approximate densities of $1200 \mathrm{~kg} \mathrm{~m}^{-3}$ and $1600 \mathrm{~kg} \mathrm{~m}^{-3}$, respectively. Figure 1 shows the particle size distribution of the fine aggregate as obtained by the sieve analysis method and fly ash. The particle size distribution limitation was determined following the ASTM C33 standard, in which the standard size sieves for fine aggregate have openings ranging from $150 \mu \mathrm{m}$ to $9.5 \mathrm{~mm}$. The prepared substrate samples were continuously cured in water for 28 days. However, to ensure that the hydration process occurring during the curing time is relatively complete, the samples were taken from the water and wrapped using a plastic film, then kept for 60 days at ambient temperature.
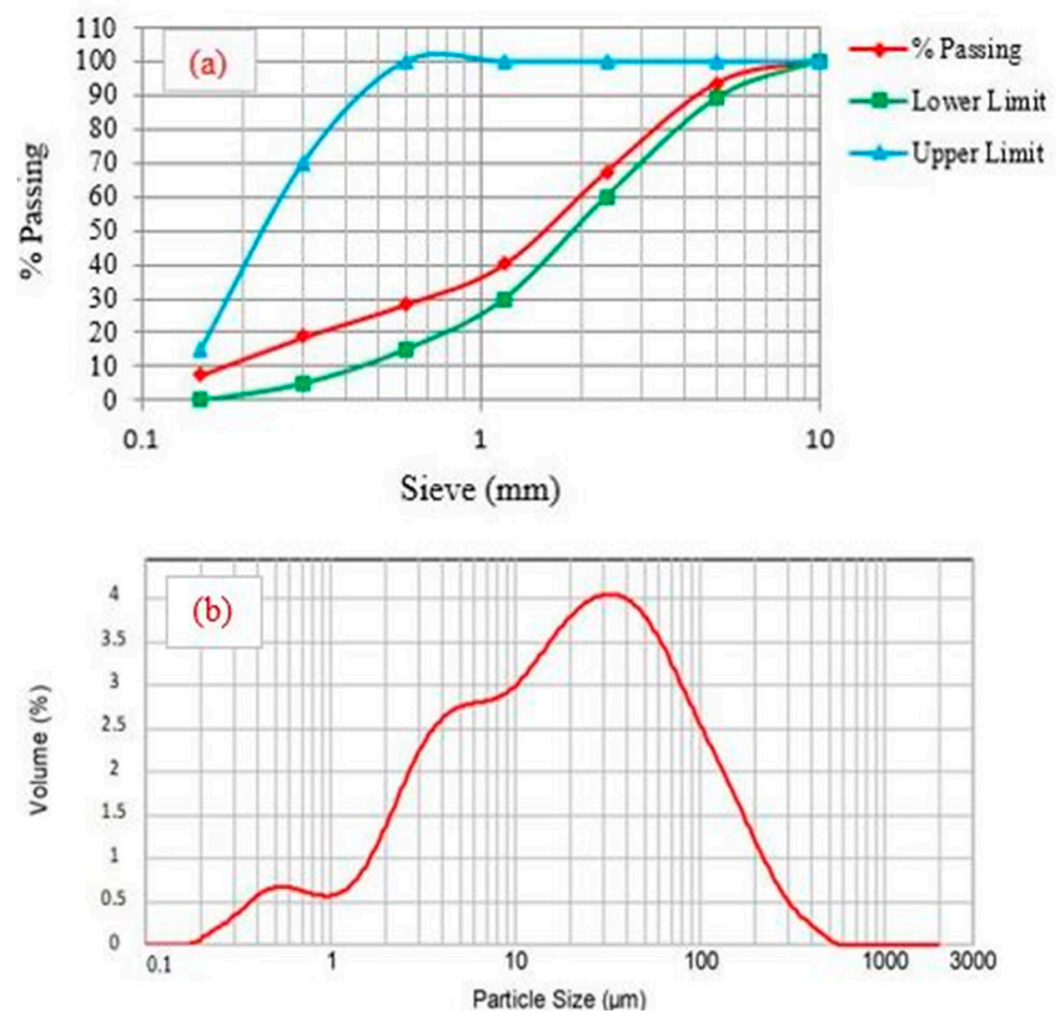

Figure 1. The particle size distribution of; (a) sand, (b) fly ash (FA). 
Table 2. Mix proportion and strength of OPC.

\begin{tabular}{|c|c|c|c|c|c|}
\hline \multirow{2}{*}{ Components } & \multirow{2}{*}{ OPC $\left(\mathrm{kg} \mathrm{m}^{-3}\right)$} & \multicolumn{2}{|c|}{ Aggregates (kg m $\left.{ }^{-3}\right)$} & \multirow{2}{*}{ Water $\left(\mathrm{kg} \mathrm{m}^{-3}\right)$} & \multirow{2}{*}{$\begin{array}{c}\text { Properties of OPC } \\
\text { fc (MPa) }\end{array}$} \\
\hline & & Fine & Coarse & & \\
\hline Proportions & 410 & 648 & 1152 & 205 & 30 \\
\hline
\end{tabular}

\subsection{Experimental Testing}

\subsubsection{Setting Time}

Initial and final setting times of the fresh geopolymer paste were measured in accordance with ASTM C403 standard method $[19,20]$. The initial setting time started when the liquid phase was added to the binder until the time when the paste starts losing its elasticity. Whereas, the final setting time elapsed from the time when the geopolymer paste completely loses its elasticity.

\subsubsection{Compressive Strength Test}

The compressive strength was performed using an Instron machine series 5569 Mechanical Tester of the loading capacity of $3000 \mathrm{~N}$. The strength was determined under a loading rate of $0.5 \mathrm{~N} \mathrm{~mm}^{-2} \mathrm{~s}^{-1}$, in accordance with the ASTM C109 standard [21]. All tests were conducted in triplicate and average values were considered and used.

\subsubsection{Bonding Test}

A slant shear test is adopted to determine the bond strength between fly ash-based geopolymer paste and OPC concrete. This test method was performed to evaluate the bond strength between old and new overlay concrete as described in ASTM C882 standard [22]. To prepare specimens for the slant shear test, a $50 \mathrm{~mm} \times 50 \mathrm{~mm} \times 125 \mathrm{~mm}$ prism mould was used, in which the first half part was filled by OPC concrete as a substrate, whereas the second half part was filled by flay ash-based geopolymer paste as a repair material as shown in Figure 2.

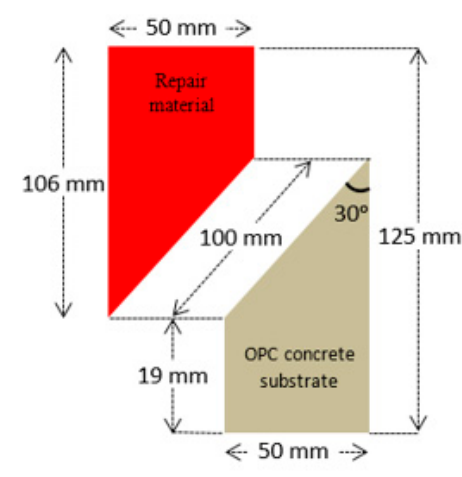

(a)

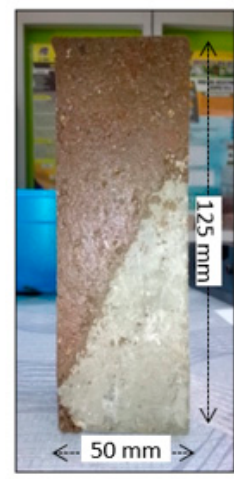

(b)

Figure 2. Schematic diagram presents; (a) slant shear test features, (b) prepared sample.

The slant shear test samples were prepared using an OPC concrete with the mix proportion illustrated in Table 2. The OPC concrete mix was firstly prepared and poured into the prism moulds until half was filled (Figure 2). The samples were wrapped using a plastic film, then cured for 28 days at room temperature of $24 \pm 2{ }^{\circ} \mathrm{C}$ and relative humidity of $75-85 \%$. After 28 days of curing, the pre-prepared half part OPC concrete samples were used as a substrate for fly ash-based geopolymer paste, where the second half was filled by using FA-based geopolymer paste. The final samples were wrapped using a plastic film and, then cured at room temperature of $24 \pm 2{ }^{\circ} \mathrm{C}$ and relative humidity of $75 \%-85 \%$ for $24 \mathrm{~h}$. Then they were demoulded and wrapped with plastic film to prevent any moisture loss and left 
at ambient temperature for 14 days before being tested. The purpose of this test was to evaluate the bonding strength between old OPC concrete substrate and FA-based geopolymer paste, including both the compressive strengths of the OPC substrate and the new overlay geopolymer paste.

\subsubsection{Phase Characterization}

To characterize and identify various crystalline and semi-crystalline phases of both raw material and different FA-based geopolymer pastes, X-ray diffraction (XRD) was used. An XRD-6000 SHIMADZU $X$-Ray Diffractometer model with $\mathrm{Cu}$-Ka radiation generated under a voltage of $44 \mathrm{kv}$ at ambient condition was used to analyze five selected specimens including raw FA and FA-based geopolymer pastes made from $8,10,12$ and $14 \mathrm{M}$ of $\mathrm{NaOH}$. The XRD analysis was performed at a scanning angle $2 \theta$ ranged between 10 and $80^{\circ}$ with a step of $0.010^{\circ}$ per second. Afterwards, the diffraction patterns were examined using the " $X^{\prime}$ Pert HighScore Plus" software for auto-matching of the peaks.

\subsubsection{Microstructure Characterization}

A scanning electron microscope (SEM) JSM-6460LA (JEOL) Japan model equipped with an energydispersive X-ray (EDX) analyzer, was used for microstructural analysis. The samples were in the form of solid in which were typically selected from the zones where half is the geopolymer and the other half is the OPC concrete substrate as shown in Figure 3. In order to ensure that the interface areas between the FA-based geopolymer paste and the OPC substrate are clearly visible, all samples were firstly polished using grinding papers of 320 grit, then the obtained surfaces were metalized with palladium using an Auto Fine Coater JEOL JFC 1600 model.
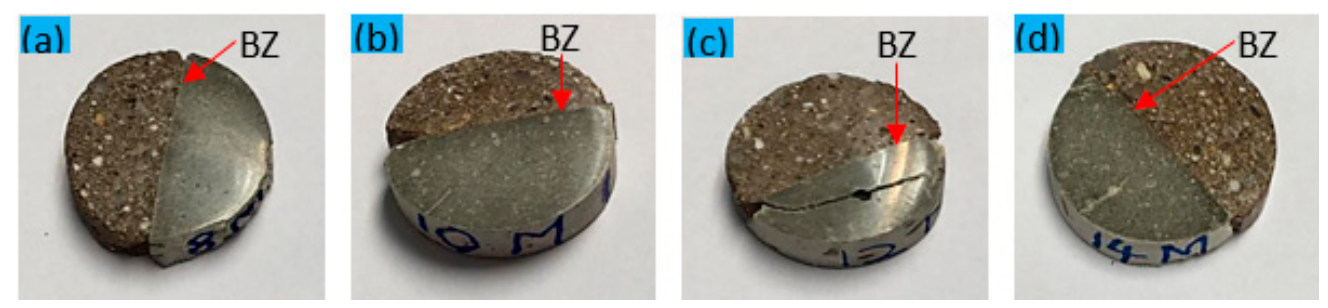

Figure 3. The bonding zone (BZ) between the FA-based geopolymer specimens and OPC substrate at: (a) $8 \mathrm{M}$, (b) $10 \mathrm{M}$, (c) $12 \mathrm{M}$ and (d) $14 \mathrm{M}$.

\section{Results and Discussion}

\subsection{Setting Time of FA-Based Geopolymer Repair Material}

Figure 4 displays the setting times of FA-based geopolymer paste produced. It can be seen from the same figure that the initial and the final setting times range from 40 to $22 \mathrm{~min}$ and 53 to $30 \mathrm{~min}$ with respect to $\mathrm{NaOH}$ concentration of $8 \mathrm{M}$ to $14 \mathrm{M}$, respectively. Both setting times are negatively proportional to the $\mathrm{NaOH}$ concentration, in which the setting time of FA-based geopolymer paste material decreases with the increase of $\mathrm{NaOH}$ molarity in the activator solution. The authors believed that a high concentration of $\mathrm{NaOH}$ solution plays a significant role in dissolving various mineral oxides of the fly ash, in particular, aluminium, silicate and iron oxides in which their content is majoritarian in the FA. In other words, using a high concentration of alkaline solution accelerates what is called geopolymerization process, which in turn occurred due to a faster dissolution of $\mathrm{Si}^{4+}$ and $\mathrm{Al}^{3+}$ then leading to the formation of sodium alumina-silicate hydrate (N-A-S-H) and calcium alumina-silicate hydrate (C-A-S-H) gels. The physical properties of the FA has also an important effect of both workability and setting times of geopolymers [23]. Therefore, the considerable amount of calcium oxide $(\mathrm{CaO})(18.4 \%)$ in the prime material is believed to have a substantial effect on the setting time of the final geopolymer product [1]. The selectivity and the high reactivity of $\mathrm{CaO}$ in the presence of a quasi-strong alkaline solution permit 
to earlier formation of chemical cross-links between the $\mathrm{Ca}^{++}$cations and other different cations in the geopolymeric system, in which strong bonds of the C-A-S-H gel are built.

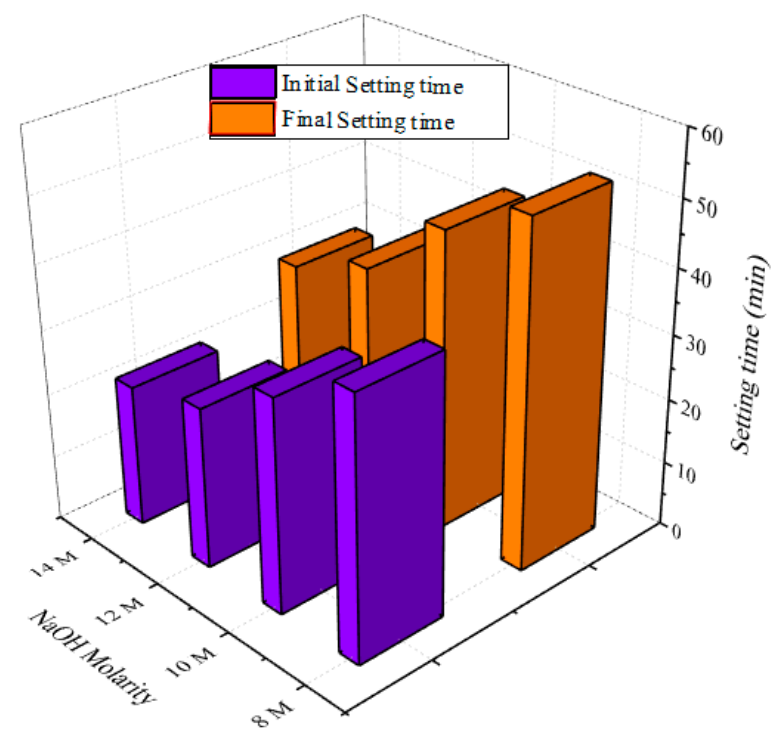

Figure 4. Setting time of FA-based geopolymer paste vs. $\mathrm{NaOH}$ molarity.

It has been reported that during the mixing process, a quantity of heat is generated due to an exothermic reaction occurred at an early stage of geopolymerization. The quantity of heat generated is believed to be a result of the dissolution of various element oxides in the raw material by the alkaline activator, where a rupture of bonds occurred, and at the same time allowed the resulted cations and anions to build new bonds in a gel forms. This provides additional benefits in terms of improving the strength at early stages due to the faster formation of gels, hence decreasing the setting time of the mixture [24,25].

\subsection{Compressive Strength of FA-Based Geopolymer Repair Material}

Figure 5 exhibits the compressive strength of FA-based geopolymer paste in the function of $\mathrm{NaOH}$ concentrations at different curing ages. It can be observed from the same figure and in respect of $\mathrm{NaOH}$ molarity that the compressive strength has a significant improvement during the curing periods of 3 , 14, 28, and 60 days. Furthermore, the FA-based geopolymer paste has developed a noticeable strength at different ages where the $\mathrm{NaOH}$ molarity has been varied from 8 to $12 \mathrm{M}$. Nevertheless, at $14 \mathrm{M}$ of $\mathrm{NaOH}$ solution, the compressive strength slightly decreased by $13.8 \%$ and $18.9 \%$ after 60 days when compared to that of 10 and $12 \mathrm{M}$, respectively. The increase in compressive strength at different $\mathrm{NaOH}$ molarity with time could be due to the high dissolution of FA content in the mixture, in which the geopolymerization process became faster, then led to an earlier formation of geopolymer gels, which in turn causes of a reduction of setting time.

The compressive strength was found to decrease when $14 \mathrm{M}$ of $\mathrm{NaOH}$ solution was used. This indicates that an excess of alkaline solution negatively affects the strength development. This is believed to be due to the excess regeneration amounts of $\mathrm{OH}^{-}$and $\mathrm{Na}^{+}$ions, which in turn causes a geopolymeric congestion system, then inhibits the continuity of the formation of the geopolymeric gels. The optimal compressive strengths at 3,14, 28, and 60 days were observed to be 32.8, 47.4, 76.5, and $92.5 \mathrm{MPa}$, respectively, which correspond to the optimal $\mathrm{NaOH}$ concentration of $12 \mathrm{M}$ with a significant improvement of $95.1 \%$ after 60 days of curing. Similar studies have shown the effect of $\mathrm{NaOH}$ molarity on geopolymerization, where the results revealed that $12 \mathrm{M}$ is a sufficient concentration to obtain high strengths [26]. Furthermore, the increase of sodium hydroxide concentration leads to a high dissolution of the silica and alumina in which more cations (Si4+ and $\mathrm{Al} 3+$ ) will be generated, which in turn contributes to the creation of new bonds during the gel-building phase [27]. This improvement in strength is mainly due to the presence of 
quasi-high amounts of $\mathrm{CaO}$, which is $18.4 \%$ of the total amount of FA mass. Furthermore, the dissolution of $\mathrm{CaO}$ components leads to the formation of C-A-S-H gel, besides the formation of N-A-S-H gel as a result of the incorporation of $\mathrm{Si}^{4+}$ and $\mathrm{Al}^{3+}$ with the activator solution, and this leads to the improvement of strength [1,23]. To explain the main chemical mechanism occurring during the geopolymerization process, Equation (1) shows the chemical reaction which converts the silica and aluminium crystals into aqueous phases in the presence of sodium hydroxide solution.

$$
\left(\mathrm{SiO}_{2}, \mathrm{Al}_{2} \mathrm{O}_{3} \text { from fly ash }\right)+2 \mathrm{NaOH}+5 \mathrm{H}_{2} \mathrm{O} \rightarrow \mathrm{Si}(\mathrm{OH})_{4}+2 \mathrm{Al}(\mathrm{OH})_{4}{ }^{-}+2 \mathrm{Na}^{+}
$$

It should be noted that the presence of a sufficient amount of iron oxide $\left(\mathrm{Fe}_{2} \mathrm{O}_{3}\right)$ of $19.57 \%$ of the total mass of FA has contributed to the strength enhancement of the final geopolymer product. This is due to a typical formation of a new gel phase known as ferrosialate gel as a result of the incorporation of $\mathrm{Fe}^{+2}$ with the activator solution and other ions from the geopolymeric system via a similar chemical process as the $\mathrm{Si}^{4+}, \mathrm{Al}^{3+}$, and $\mathrm{Ca}^{2+}$. This was stated by Cannio et al. (2018) [28] where the ferrosialate has been identified in a geopolymer mix.

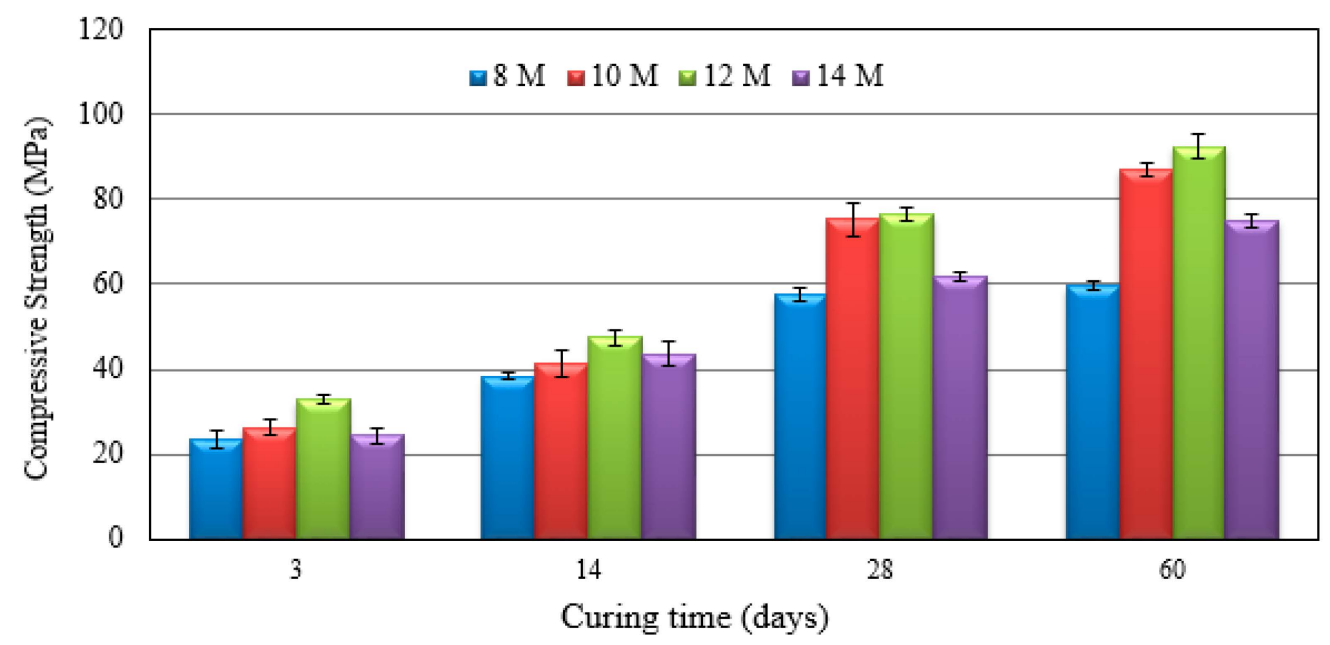

Figure 5. Compressive strengths of FA-based geopolymer paste with various $\mathrm{NaOH}$ molarity.

\subsection{Bonding Strength between FA-Based Geopolymer Paste and OPC Concrete Substrate}

It is obvious from Figure 6 that the bonding strength obtained between FA-based geopolymer paste and the OPC substrate exhibits behaviour similar to the compressive strength of the FA-based geopolymer. From the same figure, the shear bonding strength between both OPC substrate and the FA-based geopolymer repair material strongly depends on the $\mathrm{NaOH}$ concentration, which increased with the increase of the $\mathrm{NaOH}$ molarity. However, at a certain concentration of $14 \mathrm{M}$, the shear bonding strength slightly decreased by $16.36 \%$ from that value at $12 \mathrm{M}$. The decrease which is shown at $14 \mathrm{M}$ can be explained by the non-complete dissolution process of FA, which has been affected by the excess amounts of ions in the geopolymeric system, this leads to chemical congestion of those excess ions which in turn inhibits if not delays the dissolution process of the precursor (FA) hence, contribute in the formation of effloresces gel as will be explained later in this section.

The increase of slant shear bond strength may be due to the presence of a sufficient amount of $\mathrm{CaO}$ in the prime material. During the geopolymerization process, the formation of C-A-S-H gel occurred faster due to the high reactivity and selectivity of $\mathrm{Ca}^{2+}$ cations generated from the dissolution of $\mathrm{CaO}$, hence, this gel can also be formed by the incorporation of free cations of $\mathrm{Ca}^{2+}$ from the OPC substrate. In other words, new cross-link bonds were built between the OPC substrate and the fresh FA-based geopolymer paste via a physical reaction between the free $\mathrm{Ca}^{2+}$ cations from the surface of the OPC substrate and the fresh FA-based geopolymer paste. This interaction occurs at the interfacial transition zone and leads to a huge enhancement of the bonding zone (BZ), thus increasing the strength. 


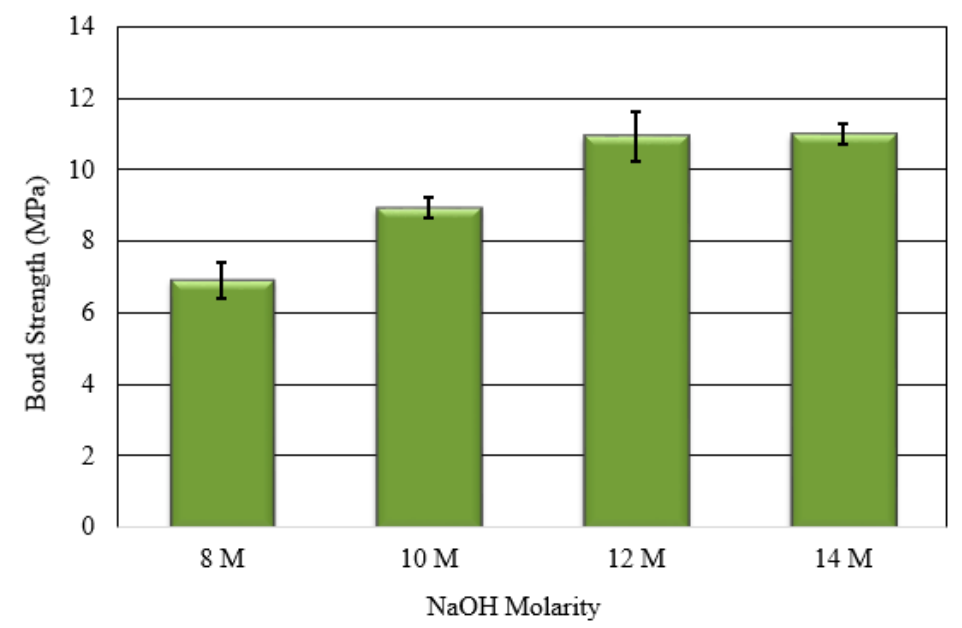

Figure 6. Bond strength of FA-based geopolymer paste with various $\mathrm{NaOH}$ molarity.

The relationship between FA-based geopolymer paste repair material and slant shear bond strength in the function of $\mathrm{NaOH}$ concentration is shown in Figure 7. It is clear that the $\mathrm{NaOH}$ concentration has a similar effect on both compressive strength and slant shear bond strength. Both trends exhibit an obvious increase from 8 to $12 \mathrm{M}$, then slightly decreased at $14 \mathrm{M}$. From the same figure, it is clear that the maximum strength which corresponds to the strong bond strength was obtained at an optimal $\mathrm{NaOH}$ concentration of $12 \mathrm{M}$. It is evident from these mechanical tests besides the morphological ones that the use of an alkaline activator with $12 \mathrm{M}$ of $\mathrm{NaOH}$ can optimize the final geopolymer mix design, in which the mechanical and microstructural properties can be improved. In other words, the presence of $\mathrm{NaOH}$ in a sufficient amount led to the achievement of a high strength of the repair material, which in fact, higher than the substrate concrete. Therefore, in this study, the designed mix of OPC concrete was C30/37 strength, where the geopolymer repair material has a maximum strength of 92.5 MPa at 60 days. This clearly explains the strong evaluation of the bonding strength between both materials and, hence, it showed the efficiency of the produced geopolymer as a repair material.

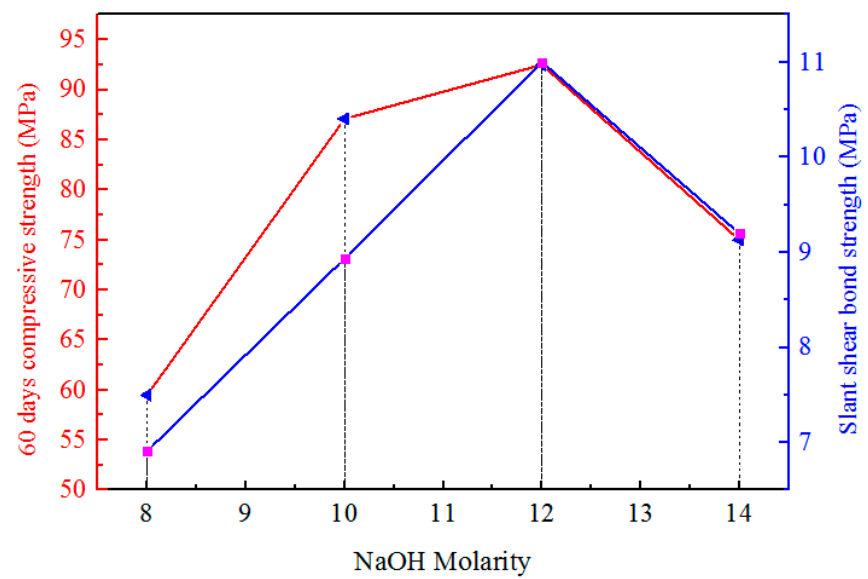

Figure 7. The relationship between overlay FA-based geopolymer paste compressive strength and slant shear bond strength.

It is worth mentioning that a high concentration of $\mathrm{NaOH}$ leads to an excess of free ions in the mixture, subsequently contributing to the formation of what is called efflorescence. This latter is a type of crystalline deposit of salts in a white or greyish tint, which is formed due to the evaporation of water in the presence of a high amount of ions such as $\mathrm{Na}^{+}$which in turn are introduced in the formation of salts. As a result of that, a reduction of strength will occur, hence a weak bonding strength will take place between the OPC substrate and FA-based geopolymer repair material $[17,29,30]$. 


\subsection{Phase Analysis}

The XRD patterns of raw FA and FA-based geopolymer paste with various $\mathrm{NaOH}$ molarities are shown in Figure 8. It can be observed from the pattern in Figure 8 that the main characterized crystalline peaks in FA were quartz $\left(\mathrm{SiO}_{2}\right)$, hematite $\left(\mathrm{Fe}_{2} \mathrm{O}_{3}\right)$, and mullite, which is well supported by $\mathrm{X}$-ray fluorescence $(\mathrm{XRF})$ analysis [1,31]. Beidellite $\left((\mathrm{Na}, \mathrm{Ca}) \mathrm{Al}_{2} \mathrm{Si}_{4} \mathrm{O}_{10}(\mathrm{OH})_{2}\right.$ was another important peak detected in all FA-based geopolymer pates with different $\mathrm{NaOH}$ concentrations at $2 \theta \sim 27^{\circ}$. When comparing the latter with that of FA at the same range of $2 \theta$, it is evident that Beidellite was formed during geopolymerization, where the $\mathrm{Na}^{+}$and $\mathrm{Ca}^{2+}$ cations have taken a place in the reaction. This also can be demonstrated by the increase of the intensity of different peaks at various $\mathrm{NaOH}$ concentrations (see Figure 8). It can be also seen from the XRD results that new crystalline peaks were identified in the pattern of all FA-based geopolymer paste, which correspond to fayalite $\left(\mathrm{Fe}_{2} \mathrm{SiO}_{4}\right)$ at $2 \theta \sim 37^{\circ}$. These new crystalline phases are believed to be formed due to the attribution of iron oxide in the geopolymeric system, in which the $\mathrm{Fe}^{+}$cation taken a place into the geopolymerization in two ways; i) firstly, a dissolution process of the hematite $\left(\mathrm{Fe}_{2} \mathrm{O}_{3}\right)$ from the raw material in the presence of alkaline activator, where various $\mathrm{Fe}^{+}$ cations are generated into the mixture; then, ii) secondly, those generated $\mathrm{Fe}^{+}$cations partially band in a chemical reaction with $\mathrm{Si}^{+4}$ by sharing the same oxygen atoms, subsequently, three-dimensional crystals of $\mathrm{Fe}_{2} \mathrm{SiO}_{4}$ are formed.

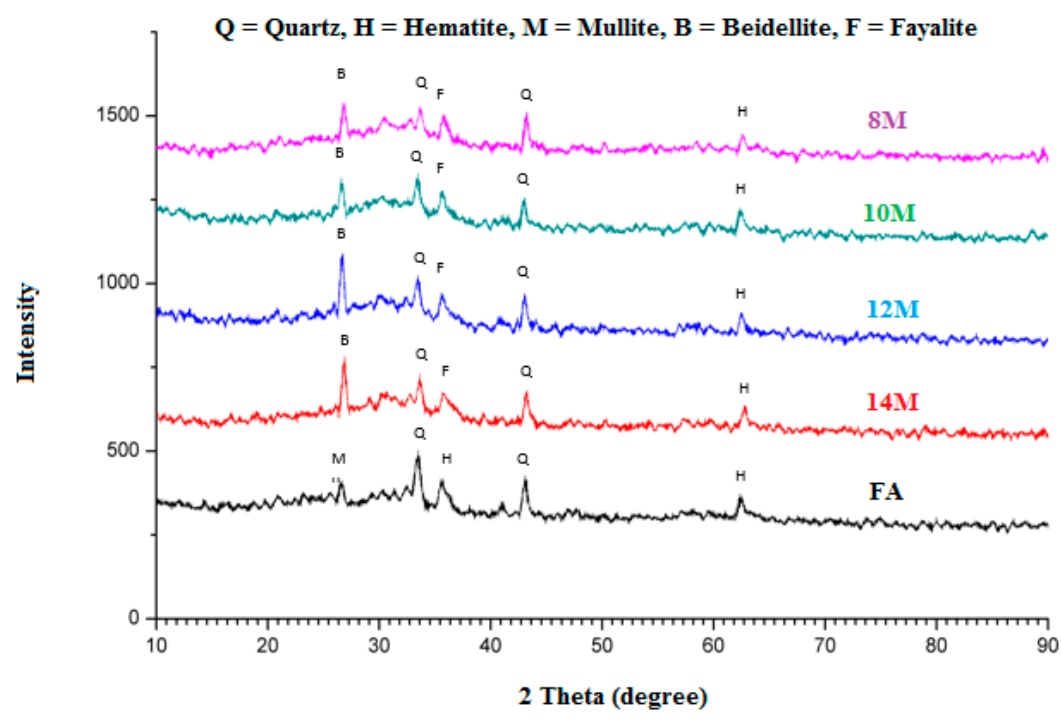

Figure 8. X-ray diffraction (XRD) analysis of precursor and FA-based geopolymer paste with various $\mathrm{NaOH}$ Molarity. $\mathrm{Q}=$ quartz $\left(\mathrm{SiO}_{2}\right.$ : PDF $\left.=01-079-1911\right), \mathrm{B}=$ beidellite $\left((\mathrm{Na}, \mathrm{Ca}) \mathrm{Al}_{2} \mathrm{Si}_{4} \mathrm{O}_{10}(\mathrm{OH})_{2} ; \mathrm{PDF}=\right.$ 00-058 2019); $\mathrm{F}=$ fayalite $\left(\mathrm{Fe}_{2} \mathrm{SiO}_{4}\right.$ : $\left.\mathrm{PDF}=00-034-0178\right), \mathrm{H}=$ hematite $\left(\mathrm{Fe}_{2} \mathrm{O}_{3}: \mathrm{PDF}=00-033-0664\right)$.

The appearance of beidellite $\left((\mathrm{Na}, \mathrm{Ca}) \mathrm{Al}_{2} \mathrm{Si}_{4} \mathrm{O}_{10}(\mathrm{OH})_{2}\right.$ and fayalite $\left(\mathrm{Fe}_{2} \mathrm{SiO}_{4}\right)$ crystalline peaks, demonstrate that after the dissolution of different element oxides in the presence of a sufficient concentration of the activator solution, new phases were built, which explains the improvement of strength, thus a great bonding strength obtained. During the geopolymerisation, the $\mathrm{Ca}^{2+}$ and $\mathrm{Na}^{+}$ions were attributed to the geopolymeric network and led to the formation of gels as given by Equation (2).

$$
\mathrm{Na}^{+}+\mathrm{Ca}^{2+}+\mathrm{Si}(\mathrm{OH})_{4}{ }^{-}+2 \mathrm{Al}(\mathrm{OH})_{4}{ }^{-} \rightarrow(\mathrm{Na}, \mathrm{Ca}) \mathrm{Al}_{2} \mathrm{Si}_{4} \mathrm{O}_{10}(\mathrm{OH})_{2} \text { (Beidellite) }
$$

Similarly, Cannio et al. (2018) [28] suggested that the formation of fayalite can occur through a chemical reaction of hydrated ferric oxyhydroxide with silica as shown in Equation (3).

$$
\text { OFeOH. } \mathrm{H}_{2} \mathrm{O}+\mathrm{Si}(\mathrm{OH})_{4} \rightarrow \mathrm{Fe}(\mathrm{OH})_{3} \cdot \mathrm{SiO}_{2}(\text { fayalite })+2 \mathrm{H}_{2} \mathrm{O}
$$




\subsection{Scanning Electron Microscope (SEM) Images at the Bonding Zone (BZ) between Geopolymer and Concrete Substrate}

Figure 9 displays the images of the interfacial transition zone (ITZ) between the FA-based geopolymer paste and OPC substrate as given by the SEM analysis. It is evident from the same figure that both geopolymer and OPC matrices can be clearly distinguished. It can also be seen from the images in Figure 9 that the FA-based geopolymer paste exhibits a denser and compact matrix with almost fully reacted FA particles. Bouaissi et al. (2019) [1] stated that the unreacted FA particles play a significant role in the development of strength. The images presented in Figure 9a-c demonstrate the geopolymerization product and clearly show the strong interfacial adhesion between the FA-based geopolymer paste and the OPC matrix. The presence of a high source of calcium and alumina-silicate in the main mixture contributed to the formation of C-A-S-H gel, which concentrates at the interfacial zone, where free ions of $\mathrm{Ca}^{2+}$ from the OPC were involved in the geopolymerization, then led to improvements of strength and bond strength. The EDX analysis (to be shown in the next section) shows that the selected zones from FA-based geopolymer paste, OPC substrate, and the interfacial zone have major elements of calcium, silicate, and aluminium, and these results are in good agreements with that of XRD.
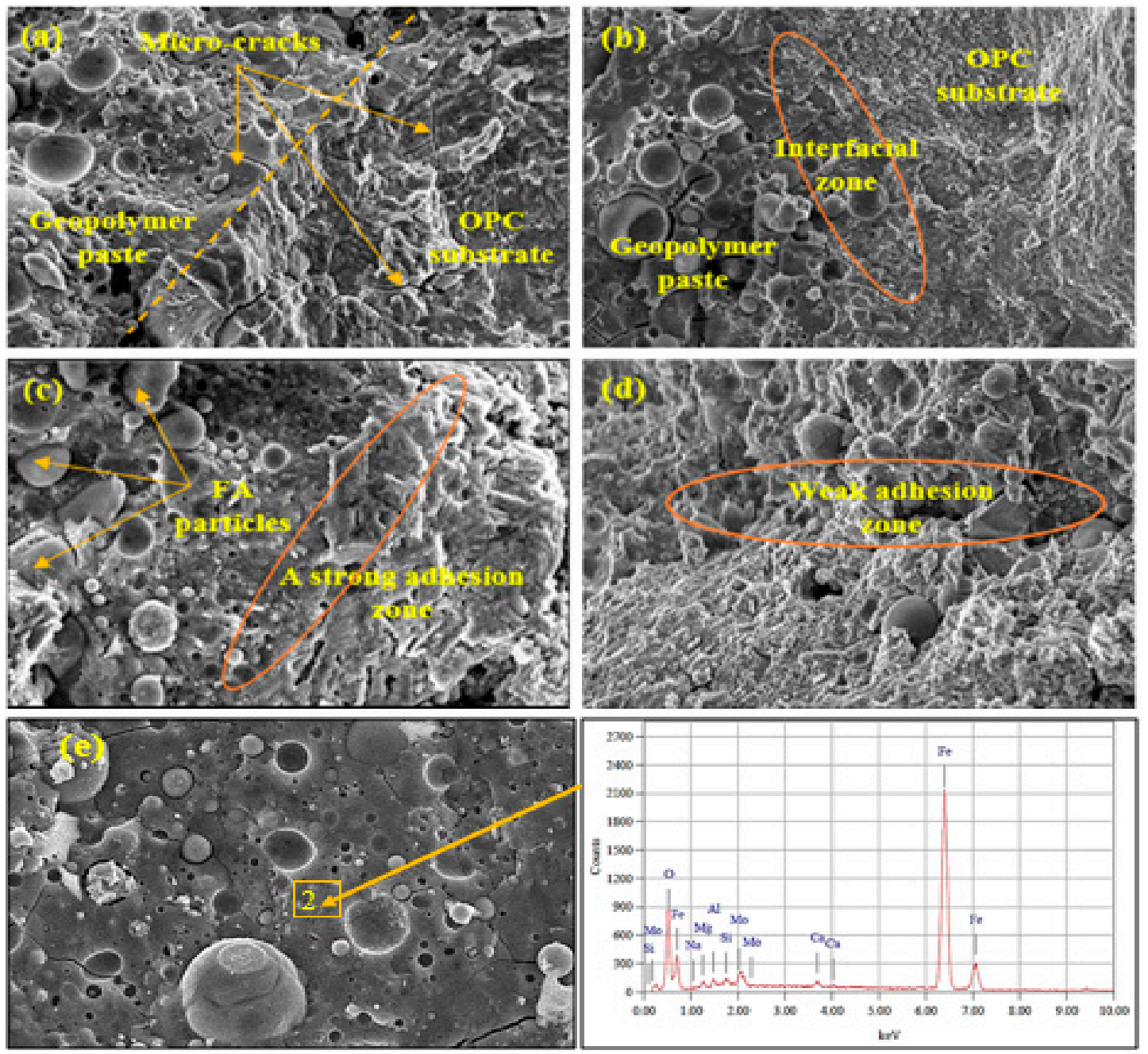

Figure 9. SEM images at the bonding zone (BZ) with; (a) 8 M, (b) 10 M, (c) 12 M, (d) 14 M, (e) energydispersive X-ray (EDX) analysis shows the contribution of iron oxide in the geopolymerization.

The micro-cracks were observed in some of the SEM images that probably occurred due to (a) the SEM samples were selected from the samples after compression tests, (b) the development of microreaction in which internal stress occurred between particles [32]. 
To understand more thoroughly the mechanism occurred at the bonding zone between the OPC substrate and FA-based geopolymer paste, EDX analysis was performed, hence approximate elemental percentages were determined. Figure 10 shows the EDX analysis of various selected areas, which were chosen from different morphological images. It is obvious from Figure 10 that the selected area at the FA-based geopolymer paste interface has major elements with approximate $\mathrm{Si} / \mathrm{Al}$ and $\mathrm{Ca} / \mathrm{Si}$ ratios of 2.71 and 0.7 , respectively. Nonetheless, those ratios were found to be 5.43 and 4.49 at the OPC substrate area, respectively. Furthermore, at the interfacial bonding zone area, those ratios were given as 2.36 and 4.10, respectively. The EDX results were in good agreement with the XRD results, which strongly demonstrate the contribution of the free ions $\mathrm{Ca}^{2+}$ located at the interfacial zone in the formation of $\mathrm{C}-\mathrm{A}-\mathrm{S}-\mathrm{H}$ gel. These ions are believed to be generated from the decomposition of calcium hydroxide $\left(\mathrm{Ca}(\mathrm{OH})_{2}\right)$ produced during the hydration process of OPC concrete. Therefore, the formation of C-A-S-H gel with a high proportion at the interfacial zone led to the improvement of both mechanical and bonding strengths of the repaired material.
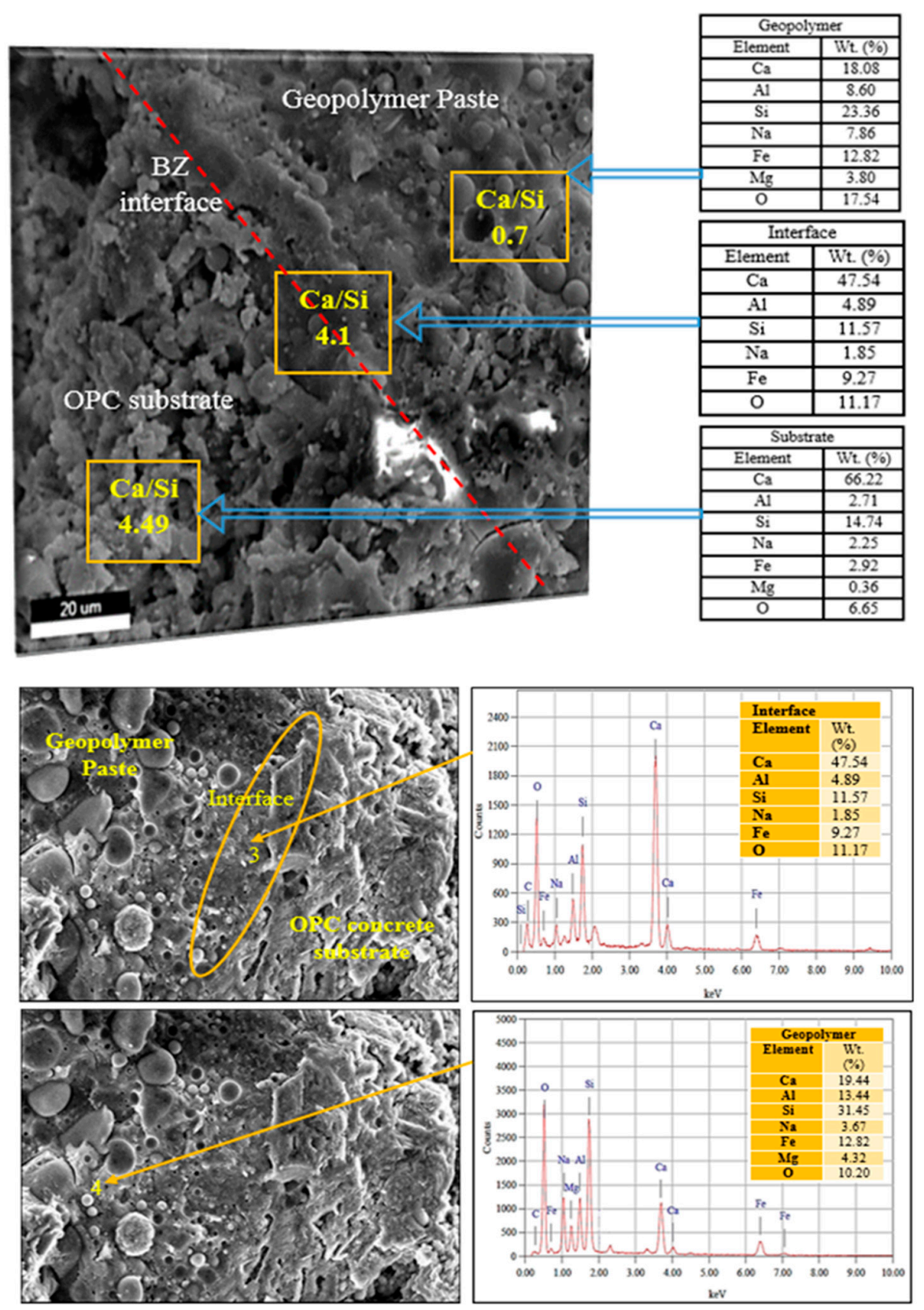

Figure 10. Elemental composition in various areas as given by EDX analysis. 
The following equations express deeply the mechanism at the interfacial bonding zone between FA-based geopolymer paste and OPC substrate.

The formation of $\left(\mathrm{C}_{3} \mathrm{~S}\right.$ and $\left.\mathrm{C}_{2} \mathrm{~S}\right)$ with water via a hydration process of calcium silicate is shown in Equations (4) and (5):

$$
\begin{gathered}
2\left(3 \mathrm{CaO} . \mathrm{SiO}_{2}\right)+6 \mathrm{H}_{2} \mathrm{O} \rightarrow 3 \mathrm{CaO} \cdot 2 \mathrm{SiO} \cdot 3 \mathrm{H}_{2} \mathrm{O}+3 \mathrm{Ca}(\mathrm{OH})_{2} \\
2\left(2 \mathrm{CaO} . \mathrm{SiO}_{2}\right)+4 \mathrm{H}_{2} \mathrm{O} \rightarrow \mathrm{CaO} \cdot 2 \mathrm{SiO} .3 \mathrm{H}_{2} \mathrm{O}+\mathrm{Ca}(\mathrm{OH})_{2}
\end{gathered}
$$

The resulting calcium hydroxide from the hydration process of $\mathrm{OPC}$, in particular, the $\mathrm{Ca}^{2+}$ ions, latter contributes with the aluminasilicate from the fresh FA-based geopolymer paste in the formation of C-A-S-H gel is expressed by Equation (6):

$$
\mathrm{SiO}_{2}(\mathrm{OH})_{4}+2 \mathrm{Al}(\mathrm{OH})_{4}{ }^{-1}+\mathrm{Ca}^{2+}(\text { from OPC }) \rightarrow[\mathrm{C}-\mathrm{A}-\mathrm{S}-\mathrm{H}] \text { gel }
$$

\section{Conclusions}

The mechanical and morphological properties of FA-based geopolymer paste as a repair material applied on OPC substrate overlay at various $\mathrm{NaOH}$ concentrations were investigated in this study. The use of FA with high calcium contents in the production of such a repair material exhibited significant mechanical and bonding strengths. A high or low $\mathrm{NaOH}$ concentration showed a substantial effect on strength development, which achieved optimal values at $12 \mathrm{M}$. The compressive strength and bond strength given at 60 days were $92.5 \mathrm{MPa}$ and $11 \mathrm{MPa}$, respectively. A strong and quasi-linear relationship was found between the compressive strength and the interfacial bonding strength.

The SEM analysis revealed that the FA-based geopolymer repair material is highly denser with fewer pores, and this is due to the formation of new crystalline phases such as Beidellite and fayalite. The EDX results confirm that the free ions of $\mathrm{Ca}^{2+}$ from the OPC substrate surface contributed to the formation of C-A-S-H gel, which in turn enhances the strengths.

The setting time was found to be decreased when the $\mathrm{NaOH}$ molarity increased, due to the high formation of different geopolymer gels, in particular, C-A-S-H gel at the interface zone, where the high concentration of calcium cations located.

Author Contributions: A.B.: Writing the original version, analysis and interpretation of data, submitting corresponding and corrections, submit the final approval of the version. W.W.A.Z.: Lab work, investigation and data collection, conception. M.M.A.B.A.: Conception, visualisation, supervisory. R.A.R.: data collection, design, supervisory. S.Y.: Lab analysis results, testing facilities and sources. M.A.A.M.S.: Lab facilities, data collection. M.R.R.M.A.Z.: Visualisation, sources, materials. H.F.: Sources, data collection. All authors have read and agreed to the published version of the manuscript.

Funding: This research received no external funding.

Acknowledgments: The authors wish to deliver their gratitude to the funding support from "Partnership for Research in Geopolymer Concrete" (H2020-MSCA-RISE-2015-689857-PRIGeoC) sponsored by the European Union, National Research and Innovation Agency, Ministry of Research and Technology, Indonesia for funding and support on the World Class Professor (WCP) Program 2019 and the National Metal and Materials Technology Center (MTEC) for their countless inputs and the best technical support.

Conflicts of Interest: The authors declare no conflict of interest.

\section{References}

1. Bouaissi, A.; Li, Y.L.; Abdullah, M.M.A.B.; Bui, Q.B. Mechanical properties and microstructure analysis of FA-GGBS-HMNS based geopolymer concrete. Constr. Build. Mater. 2019, 210, 198-209. [CrossRef]

2. Malhotra, V.M. Introduction: Sustainable development and concrete technology. Concr. Int. 2002, $24,22$.

3. Davidovits, J. Geopolymers-Inorganic polymeric new materials. J. Therm. Anal. 1991, 37, 1633-1656. [CrossRef] 
4. Ranjbar, N.; Mehrali, M.; Alengaram, U.J.; Metselaar, H.S.C.; Jumaat, M.Z. Compressive strength and microstructural analysis of fly ash/palm oil fuel ash based geopolymer mortar under elevated temperatures. Constr. Build. Mater. 2014, 65, 114-121. [CrossRef]

5. Pacheco-Torgal, F.; Castro-Gomes, J.P.; Jalali, S. Adhesion characterization of tungsten mine waste geopolymeric binder. Influence of OPC concrete substrate surface treatment. Constr. Build. Mater. 2008, 22, 154-161. [CrossRef]

6. Part, W.K.; Ramli, M.; Cheah, C.B. An Overview on the Influence of Various Factors on the Properties of Geopolymer Concrete Derived From Industrial Byproducts. Constr. Build. Mater. 2015, 77, 370-395. [CrossRef]

7. Pacheco-Torgal, F.; Abdollahnejad, Z.; Miraldo, S.; Baklouti, S.; Ding, Y. An overview on the potential of geopolymers for concrete infrastructure rehabilitation. Constr. Build. Mater. 2012, 36, 1053-1058. [CrossRef]

8. Komnitsas, K.; Zaharaki, D. Geopolymerisation: A review and prospects for the minerals industry. Miner. Eng. 2007, 20, 1261-1277. [CrossRef]

9. Provis, J.L.; van Deventer, J.S.J. Geopolymerisation kinetics. 2. Reaction kinetic modelling. Chem. Eng. Sci. 2007, 62, 2318-2329. [CrossRef]

10. Fernández-Jiménez, A.; Palomo, A.; Criado, M. Microstructure development of alkali-activated fly ash cement: A descriptive model. Cem. Concr. Res. 2005, 35, 1204-1209. [CrossRef]

11. Phoo-ngernkham, T.; Maegawa, A.; Mishima, N.; Hatanaka, S.; Chindaprasirt, P. Effects of sodium hydroxide and sodium silicate solutions on compressive and shear bond strengths of FA-GBFS geopolymer. Constr. Build. Mater. 2015, 91, 1-8. [CrossRef]

12. Alanazi, H.; Yang, M.; Zhang, D.; Gao, Z. Bond strength of PCC pavement repairs using metakaolin-based geopolymer mortar. Cem. Concr. Compos. 2016, 65, 75-82. [CrossRef]

13. Laskar, S.M.; Talukdar, S. Preparation and tests for workability, compressive and bond strength of ultra-fine slag based geopolymer as concrete repairing agent. Constr. Build. Mater. 2017, 154, 176-190. [CrossRef]

14. Collins, F.; Sanjayan, J.G. Effects of ultra-fine materials on workability and strength of concrete containing alkali-activated slag as the binder. Cem. Concr. Res. 1999, 29, 459-462. [CrossRef]

15. ASTM C618. Standard Specification for Coal Fly Ash and Raw or Calcined Natural Pozzolan for Use as a Mineral Admixture in Concrete. In Annual Book of ASTM Standards; American Society for Testing and Materials: West Conshohocken, PA, USA, 2001; Volume 04.02.

16. Mustafa Al Bakri, A.M.; Kamarudin, H.; Bnhussain, M.; Abd Razak, R.; Yahya, Z. Effect of Na2SiO3/NaOH ratios and $\mathrm{NaOH}$ molarities on compressive strength of fly-ash-based geopolymer. ACI Mater. J. 2012, 109, 503-508.

17. Malkawi, A.B.; Fadhil, M.; Fauzi, A.; Almattarneh, H. Effects of Alkaline Solution on Properties of the HCFA Geopolymer Mortars. Procedia Eng. 2016, 148, 710-717. [CrossRef]

18. Abdullah, M.M.A.B.; Kamarudin, H.; Bnhussain, M.; Ismail, K.N.; Ibrahim, W.M. Mechanism and Chemical Reaction of Fly Ash Geopolymer Cement- A Review. Int. J. Pure Appl. Sci. Technol. 2001, 6, 35-44.

19. ASTM C403. Standard Test Method for Time of Setting of Concrete Mixtures by Penetration Resistance. In Annual Book of ASTM Standards; American Society for Testing and Materials: West Conshohocken, PA, USA, 2003; Volume 04.02.

20. Williamson, T.; Juenger, M.C.G. The role of activating solution concentration on alkali-silica reaction in alkali-activated fly ash concrete. Cem. Concr. Res. 2016, 83, 124-130. [CrossRef]

21. ASTM C109. Standard Test Method for Compressive Strength of Hydraulic Cement Mortars. In Annual Book of ASTM Standards; American Society for Testing and Materials: West Conshohocken, PA, USA, 2016; Volume 04.01.

22. ASTM C882. Standard Test Method for Bond Strength of Epoxy-Resin Systems Used With Concrete. In Annual Book of ASTM Standards; American Society for Testing and Materials: West Conshohocken, PA, USA, 2005; Volume 04.02.

23. Ismail, I.; Bernal, S.A.; Provis, J.L.; San Nicolas, R.; Brice, D.G.; Kilcullen, A.R.; Hamdan, S.; van Deventer, J.S. Influence of fly ash on the water and chloride permeability of alkali-activated slag mortars and concretes. Constr. Build. Mater. 2013, 48, 1187-1201. [CrossRef]

24. Hu, S.; Wang, H.; Zhang, G.; Ding, Q. Bonding and abrasion resistance of geopolymeric repair material made with steel slag. Cem. Concr. Compos. 2008, 30, 239-244. [CrossRef] 
25. Phoo-ngernkham, T.; Sata, V.; Hanjitsuwan, S.; Ridtirud, C.; Hatanaka, S.; Chindaprasirt, P. High calcium fly ash geopolymer mortar containing Portland cement for use as repair material. Constr. Build. Mater. 2015, 98, 482-488. [CrossRef]

26. Al Bakri Abdullah, M.M.; Kamarudin, H.; Nizar, I.K.; Bnhussain, M.; Yahya, Z.; Abd Razak, R. Correlation between Na2SiO3/NaOH Ratio and Fly Ash / Alkaline Activator Ratio to the Strength of Geopolymer. Adv. Mater. Res. 2012, 342, 189-193.

27. Hamidi, R.M.; Man, Z.; Azizli, K.A. Concentration of $\mathrm{NaOH}$ and the Effect on the Properties of Fly Ash Based Geopolymer. Procedia Eng. 2016, 148, 189-193. [CrossRef]

28. Kaze, R.C.; à Moungam, L.M.B.; Cannio, M.; Rosa, R.; Kamseu, E.; Melo, U.C.; Leonelli, C. Microstructure and engineering properties of $\mathrm{Fe} 2 \mathrm{O} 3$ ( $\mathrm{FeO}$ ) - $\mathrm{Al} 2 \mathrm{O} 3$-SiO 2 based geopolymer composites. J. Clean. Prod. 2018, 199, 849-859. [CrossRef]

29. Sabitha, D.; Dattatreya, J.K.; Sakthivel, N.; Bhuvaneshwari, M.; Sathik, S.A.J. Reactivity, workability and strength of potassium versus sodium-activated high volume fly ash-based geopolymers. Curr. Sci. 2012, 103, 1320-1327.

30. Najafi, E.; Allahverdi, A.; Provis, J.L. Efflorescence control in geopolymer binders based on natural pozzolan. Cem. Concr. Compos. 2012, 34, 25-33. [CrossRef]

31. Zailan, S.N.; Bouaissi, A.; Mahmed, N.; Abdullah, M.M. Al Bakri. Influence of ZnO Nanoparticles on Mechanical Properties and Photocatalytic Activity of Self-cleaning ZnO-Based Geopolymer Paste. J. Inorg. Organomet. Polym. Mater. 2019, 1-10.

32. Fernandez-Jimenez, A.; García-Lodeiro, I.; Palomo, A. Durability of alkali-activated fly ash cementitious materials. J. Mater. Sci. 2007, 42, 3055-3065. [CrossRef]

(C) 2020 by the authors. Licensee MDPI, Basel, Switzerland. This article is an open access article distributed under the terms and conditions of the Creative Commons Attribution (CC BY) license (http://creativecommons.org/licenses/by/4.0/). 